\title{
The use of lumbar drains in preventing spinal cord injury following thoracoabdominal aortic aneurysm repair: an updated systematic review and meta-analysis
}

\author{
Nickalus R. Khan, MD, ${ }^{1}$ Zachary Smalley, BS, ${ }^{2}$ Cody L. Nesvick, BA, ${ }^{2}$ Siang Liao Lee, MD, ${ }^{3}$ and \\ L. Madison Michael II, MD ${ }^{1,4}$ \\ ${ }^{1}$ Department of Neurosurgery, ${ }^{2}$ College of Medicine, University of Tennessee Health Science Center, Memphis, Tennessee; \\ ${ }^{3}$ Department of Surgery, Metropolitan Group Hospitals, University of Illinois at Chicago, Illinois; and ${ }^{4}$ Semmes-Murphey \\ Neurologic \& Spine Institute, Memphis, Tennessee
}

\begin{abstract}
OBJECTIVE Paraplegia and paraparesis following aortic aneurysm repair occur at a substantially high rate and are often catastrophic to patients, their families, and the overall health care system. Spinal cord injury (SCI) following open thoracoabdominal aortic aneurysm (TAAA) repair is reported to be as high as $20 \%$ in historical controls. The goal of this study was to determine the impact of CSF drainage (CSFD) on SCI following TAAA repair.
\end{abstract}

METHODS In August 2015 a systematic literature search was performed using clinicaltrials.gov, the Cochrane Library, PubMed/MEDLINE, and Scopus that identified 3478 articles. Of these articles, 10 met inclusion criteria. Random and fixed-effect meta-analyses were performed using both pooled and subset analyses based on study type.

RESULTS The meta-analysis demonstrated that CSFD decreased SCI by nearly half (relative risk $0.42,95 \%$ confidence interval $0.25-0.70 ; p=0.0009$ ) in the pooled analysis. This effect remained in the subgroup analysis of early SCI but did not remain significant in late $\mathrm{SCl}$.

CONCLUSIONS This meta-analysis showed that CSFD could be an effective strategy in preventing SCI following aortic aneurysm repair. Care should be taken to prevent complications related to overdrainage. No firm conclusions can be drawn about the newer endovascular procedures at the current time.

http://thejns.org/doi/abs/10.3171/2016.1.SPINE151199

KEY WORDS aortic aneurysm; cerebrospinal fluid; endovascular; lumbar drain; spinal cord injury; vascular disorders

$\mathrm{P}$ ARAPLEGIA remains the most devastating complication in both open and endovascular repair of thoracic and aortic aneurysms. Permanent neurological deficit is a major cause of morbidity and leads to decreased long-term survival of patients with thoracoabdominal aortic aneurysm (TAAA) repair; ${ }^{13,46}$ the incidence of paraplegia has been reported to be as high as $20 \%$ in the early 1990s. ${ }^{46}$ Risk factors identified for developing spinal cord injury (SCI) following TAAA repair include aneurysm extent (related to the number of segmental arteries), location of the aneurysm (lumbar aneurysms have less robust collateral arteries), and prolonged aortic cross-clamping times. All of these risk factors point toward an ischemia/ infarction model for the pathophysiology of SCI following TAAA repair. ${ }^{22}$ Anatomical work performed by Etz et al. resulted in a better understanding of the relationship between segmental and radicular arteries.$^{20}$ This work has influenced our knowledge of ischemic injuries that occur during TAAA repair. A variety of measures to attenuate the ischemic pathophysiology have been investigated, such as elevation of mean arterial pressure, reattaching critical segmental arteries, and CSF drainage (CSFD). ${ }^{2,10,12,15,21,38,41}$ The introduction of CSFD and adjunctive neuroprotective therapies have reduced the risk of SCI to $4 \%-7 \%$ in the current literature. ${ }^{1,3,19,23,32,50}$ The first reports of CSFD as an adjunctive measure for reducing the risk of paraple-

ABBREVIATIONS $\mathrm{Cl}=$ confidence interval; $\mathrm{CSFD}=\mathrm{CSF}$ drainage; $\mathrm{df}=$ degrees of freedom; NNT = number needed to treat; NOS = Newcastle-Ottawa Scale; OCEBM = Oxford Center for Evidence-Based Medicine; OR = odds ratio; RCT = randomized controlled trial; RR = relative risk; SCI = spinal cord injury; TAAA = thoracoabdominal aortic aneurysm; TEVAR = thoracic endovascular aortic repair.

SUBMITTED October 7, 2015. ACCEPTED January 15, 2016.

INCLUDE WHEN CITING Published online April 8, 2016; DOI: 10.3171/2016.1.SPINE151199. 
gia following aortic aneurysm repair were from a seminal report on a canine model by Miyamoto et al. in 1960 and Blaisdell and Cooley in 1962.6,35 This topic has since been addressed by several prospective cohort studies and randomized controlled trials (RCTs), resulting in 2 systematic reviews that showed significant protective odds ratios (ORs) of 0.30 and 0.57 in 2004 and 2012, respectively. ${ }^{8,31}$ Neurosurgeons are often consulted for insertion and management of this adjunctive therapy. It is prudent for the neurosurgical community to understand the risks, benefits, and indications of this procedure as it relates to the natural history of this disease. This systematic review and meta-analysis was undertaken to provide an updated and thorough review about the use of CSFD in TAAA repair. The primary aim of this analysis was to determine if CSFD decreases SCI following TAAA repair.

\section{Methods}

This study was conducted using the "Assessment of Multiple Systematic Reviews" (AMSTAR) measurement tool, ${ }^{42}$ and reporting was conducted according to the guidelines defined by "Meta-analysis Of Observational Studies in Epidemiology" (MOOSE) ${ }^{45}$ and "Preferred Reporting Items for Systematic reviews and Meta-Analyses" (PRISMA). ${ }^{36}$ The research question for this study was, "Does CSFD in TAAA repair decrease postoperative paraplegia and paraparesis?"

\section{Search Strategy}

The systematic search strategy involved a search through multiple electronic databases, bibliographies of relevant articles, and consultation with the senior author (L.M.M.). We electronically searched clinicaltrials.gov, The Cochrane Library, PubMed/MEDLINE, and Scopus to find English-language articles-excluding gray literature-with no timeframe restrictions in August of 2015.

The following terms in various combinations were used: aortic aneurysm, cerebrospinal fluid, endovascular, lumbar drain, paraplegia, paraparesis, and spinal cord ischemia. Three independent researchers (Z.S., C.L.N., and S.L.L.) conducted 3 separate independent literature searches with the help of librarians at the University of Tennessee Health Science Center. If there was any question as to the eligibility of an article, consensus was reached through discussion with the senior author. When necessary, additional contact was made with the authors of the articles we included to confirm data.

\section{Inclusion Criteria, Data Extraction, End Points, Definitions}

The goals of the search were to find articles that met the following inclusion criteria: 1) described a group of adult patients ( $>18$ years of age) with surgical repair of a TAAA treated with CSFD; 2) described a control group not treated with CSFD; 3 ) had the use of CSF diversion as the main treatment difference between the 2 groups; and 4) reported the number of patients and number of neurological deficits for each group. Thus, noncomparison studies, case reports, and pediatric reports were excluded.

Three separate individuals (Z.S., C.L.N., and S.L.L.) screened all potential articles and extracted data indepen- dently. The data extracted from each article included: 1) information regarding the timeframe and drainage parameters for CSF diversion; 2) the total number of participants, in both treatment and control groups; 3) early and late postsurgical neurological deficits (i.e., paraparesis, paraplegia); 4) complications related to the use of CSF diversionary procedures; and 5) length of follow-up. The level of evidence for each study was evaluated using the Oxford Centre for Evidence Based Medicine (OCEBM) guidelines (http://www. cebm.net/ocebm-levels-of-evidence/). Study quality (i.e., assessment of bias within individual studies) was determined using the $\mathrm{Jadad}^{30}$ scale for RCTs and the NewcastleOttawa Scale (NOS) for quality assessment of controlled observational cohort studies. ${ }^{49}$ Disagreements among any of the above data points were resolved through discussion among the authors.

\section{Meta-Analysis}

For each study, the numbers of neurological deficits (early and late) in patients treated with CSF diversion were identified and a relative risk (RR) was calculated. The overall risk ratio was computed using the method of DerSimonian and Laird. ${ }^{16}$ Analysis was performed using Review Manager software (version 5.3, Cochrane Collaboration 2014).

A random effects meta-analysis was performed on selected studies. A random effects model, in contrast to a fixed effects model, does not assume that the relative risk is the same across studies and yields a more conservative estimate of effect. Heterogeneity between studies was assessed by the Cochran Q test and $\mathrm{I}^{2}$ statistic. Heterogeneity is calculated by taking a weighted sum of the squared differences between individual study effect sizes and the overall pooled effect estimate. The greater the difference, the more likely it is that significant methodological and clinical differences exist between the included studies. Heterogeneity was considered statistically significant when the $\mathrm{p}$ value derived from the Cochran $\mathrm{Q}$ test was less than 0.1. For the qualitative interpretation of heterogeneity, $\mathrm{I}^{2}$ values of at least $50 \%$ are usually considered to represent substantial heterogeneity, while values of at least $75 \%$ indicate considerable heterogeneity according to the Cochrane Handbook..$^{18}$

Publication bias (i.e., assessment of bias across studies) was graphically evaluated using a funnel plot. . $^{17,43,44}$ The theory of a funnel plot is that smaller studies should have more variation in effect sizes compared with larger studies with more robust data. A plot measuring the log of the standard error (correlated to the size of the study) and overall effect should yield a symmetric funnel-shaped diagram in the absence of publication bias.

\section{Results}

\section{Search Results and Included Articles}

After a comprehensive search of PubMed/MEDLINE, Cochrane/Ovid, Scopus, and clinicaltrials.gov, we identified 3478 unique titles. Of these titles, 93 articles were identified for abstract review after excluding articles not in English $(n=624)$ and articles not directly pertinent to the use of CSFD in TAAA repair $(n=2761)$. Of these 93 arti- 
cles, 27 were identified for full-text review after excluding case reports $(n=29)$, case series $(n=19)$, commentaries and nonsystematic reviews $(n=12)$, animal studies $(n=4)$, and articles with no aortic aneurysms in the study population $(\mathrm{n}=2)$. Of these 27 articles, 17 met inclusion criteria; however, 8 had data from the same research groups with overlapping dates and were excluded. Two articles were excluded because they selected only patients at high risk of SCI for CSFD, thus no utility between lumbar drains preventing SCI could be meaningfully assessed.,26 Additionally, a single article was identified after mining the bibliographies of included articles, leaving a final total of 10 included articles comprising 1319 patients receiving lumbar drainage and 784 control patients (Fig. 1). There were 3 RCTs and 7 cohort studies. The overall quality of the evidence for the included observational studies was moderate. The average number of stars using the NOS was $5.5 \pm 2.1$ out of a maximum of 9 stars. Each of the $3 \mathrm{RCTs}^{11,13,47}$ received 3 points using the Jadad criteria. ${ }^{30}$ Table 1 lists the characteristics of each study included in this analysis.

\section{Overall SCI Following TAAA Repair}

A total of 10 studies had sufficient information to extract overall rates of both transient and permanent SCI. All but 1 study $^{4}$ showed a protective benefit against SCI when using CSFD compared with a control group. . $11,13,27,28,37,40,47,48$ The OR was 0.42 with a $95 \%$ confidence interval (CI) of $0.25-0.70$ ( $p=0.0009$; Fig. 2). A funnel plot was used to assess publication bias (Fig. 3). There was moderate, but not significant $(p=0.11)$, heterogeneity as indicated by an $\mathrm{I}^{2}$ statistic of $37 \%$. The absolute risk reduction was $7 \%$ with a number needed to treat (NNT) of 14 .

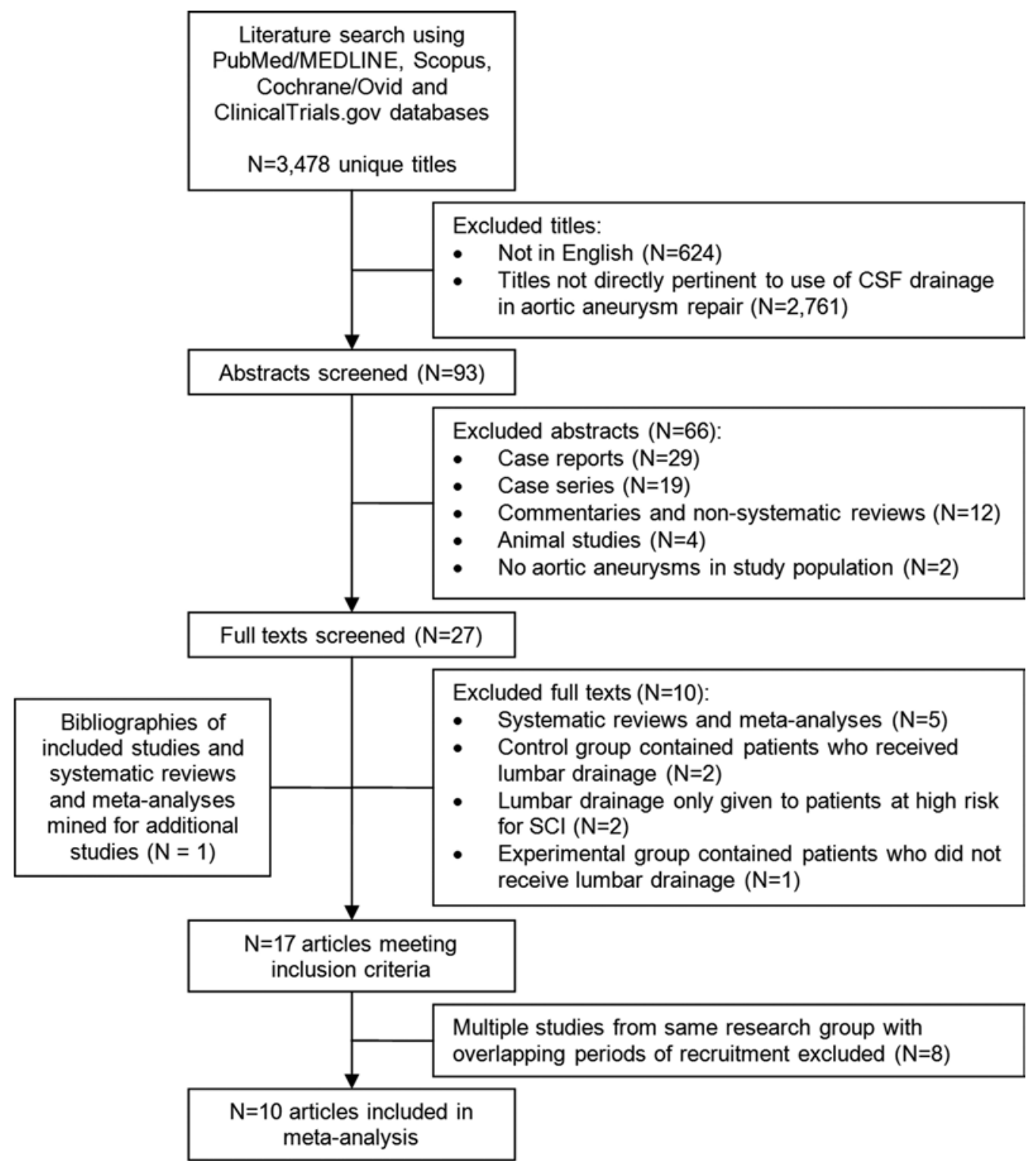

FIG. 1. Flow diagram of the search strategy used in the study. 


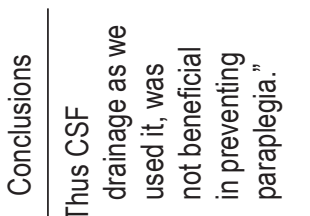

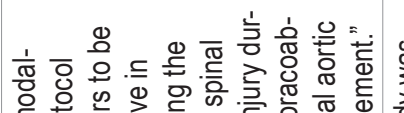

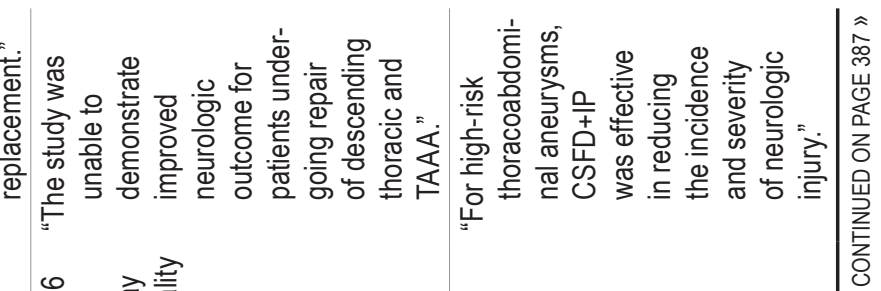

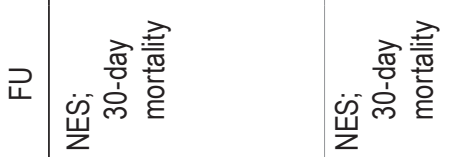

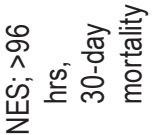

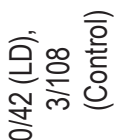

$\stackrel{\infty}{\stackrel{\infty}{\infty}}$

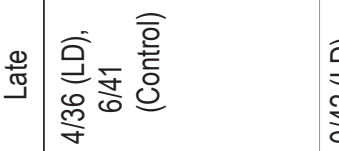

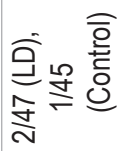

ভ

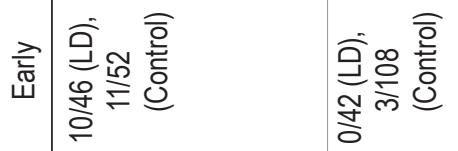

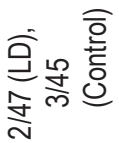

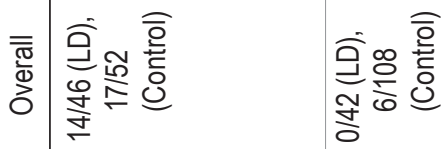

完谣

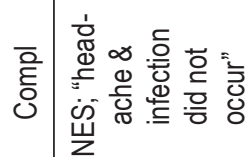

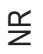

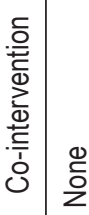

奂

品

魚

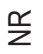

交我亮

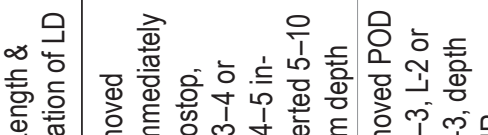

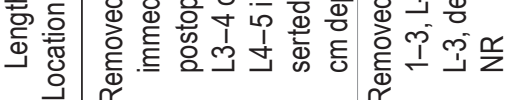

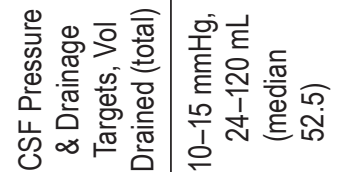

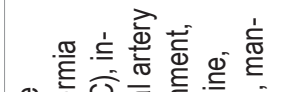

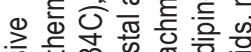

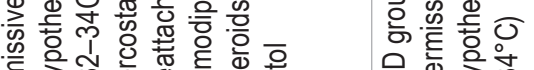

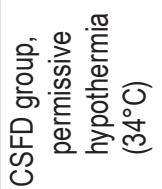

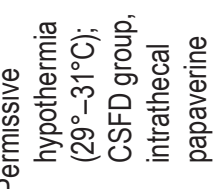

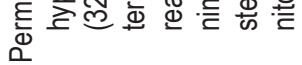

峲

这

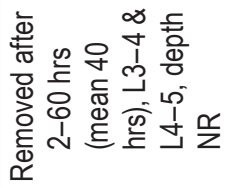

岂

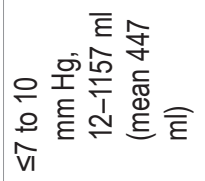

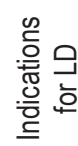

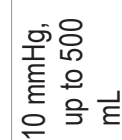

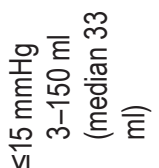

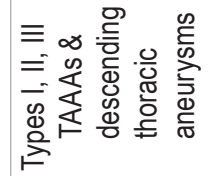

㟒

ญे

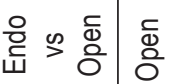

ळั ळ̆

总芯

임

옹

ह

$\frac{\sqrt{0}}{\mathscr{0}}$

to

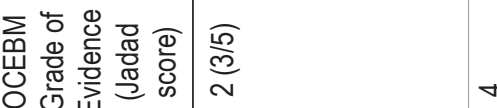

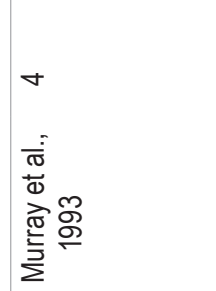

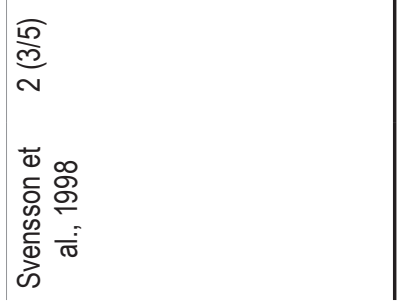




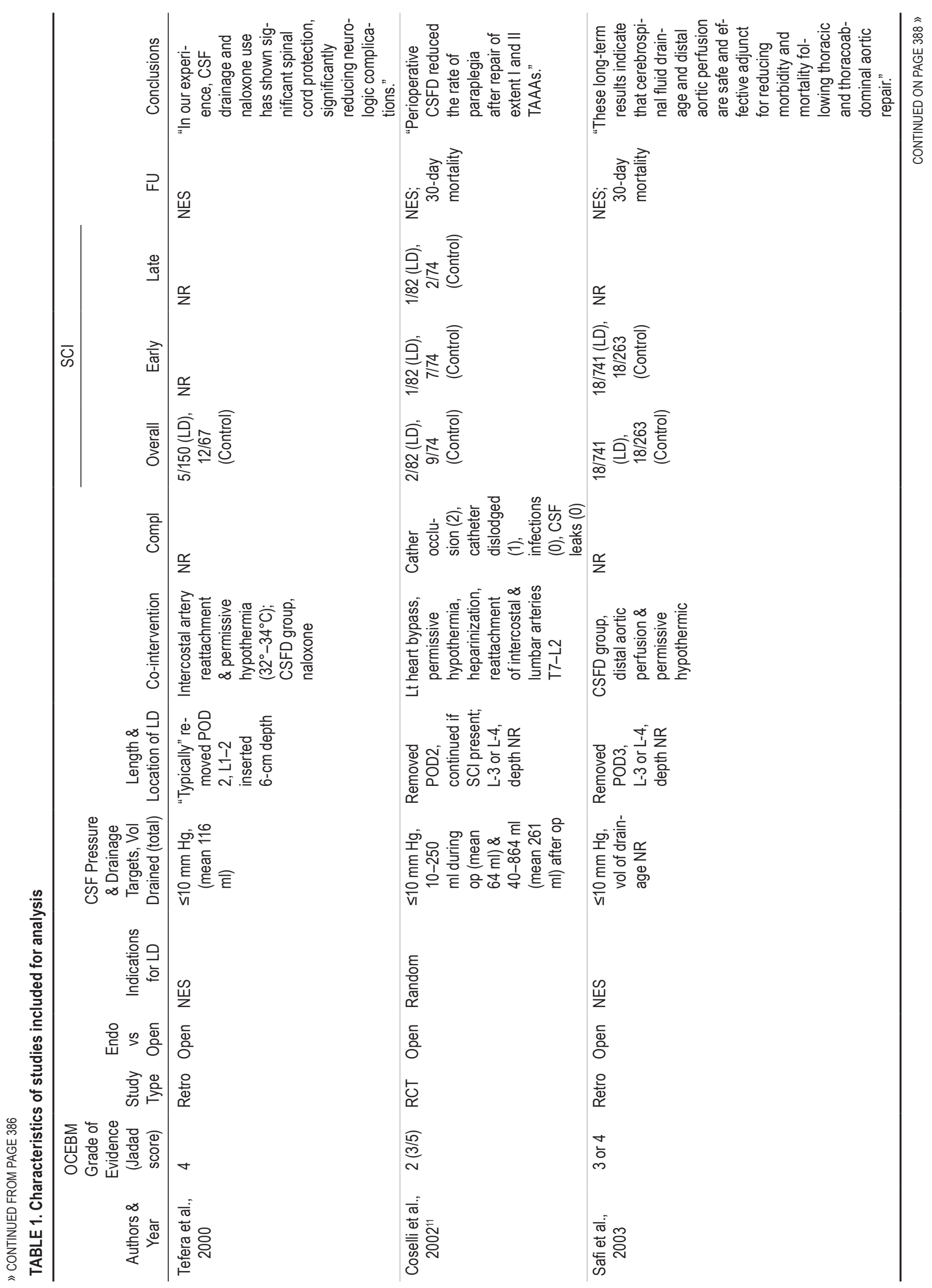




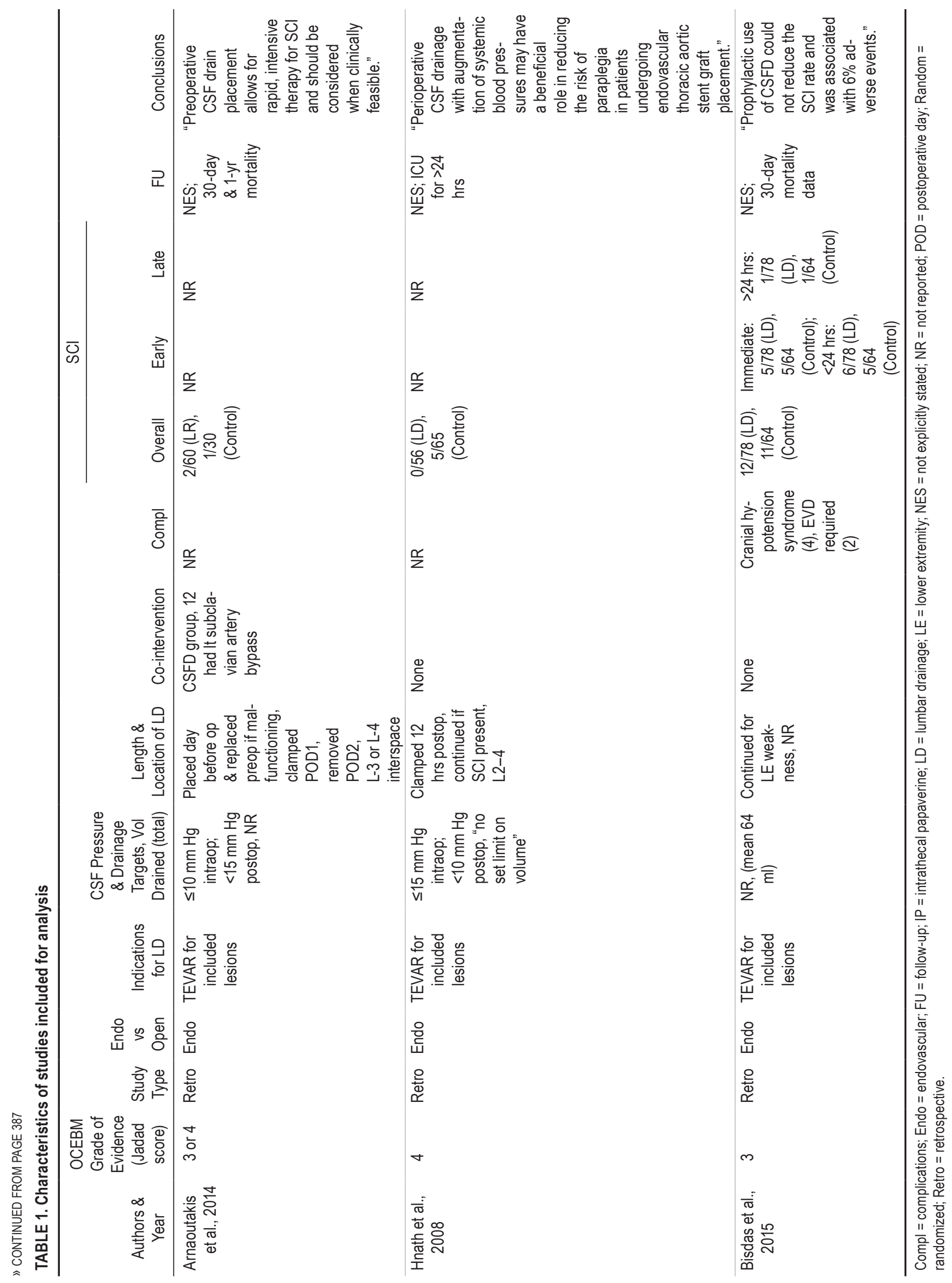




\begin{tabular}{|c|c|c|c|c|c|c|c|c|c|}
\hline Study or Subgroup & Lumbar Drain & Total & Control & $\begin{array}{l}\text { rol } \\
\text { Total }\end{array}$ & Weight & \multirow{2}{*}{$\begin{array}{l}\text { Odds Ratio } \\
\text { M-H, Random, 95\% Cl } \\
1.00[0.09,11.49]\end{array}$} & \multicolumn{3}{|c|}{$\begin{array}{c}\text { Odds Ratio } \\
\text { M-H, Random, } 95 \% \mathrm{Cl}\end{array}$} \\
\hline Arnaoutakis 2014 & 2 & 60 & 1 & 30 & $3.9 \%$ & & & & \\
\hline Bisdas 2015 & 12 & 78 & 11 & 64 & $16.1 \%$ & $0.88[0.36,2.14]$ & & & \\
\hline Coselli $2002^{11}$ & 2 & 82 & 9 & 74 & $8.1 \%$ & $0.18[0.04,0.87]$ & & & \\
\hline Crawford 1991 & 14 & 46 & 17 & 52 & $16.8 \%$ & $0.90[0.38,2.12]$ & & & \\
\hline Hnath 2008 & 0 & 56 & 5 & 65 & $2.9 \%$ & $0.10[0.01,1.80]$ & & & \\
\hline Hollier 1992 & 0 & 42 & 6 & 108 & $2.9 \%$ & $0.19[0.01,3.37]$ & & & \\
\hline Murray 1993 & 4 & 47 & 4 & 45 & $9.1 \%$ & $0.95[0.22,4.07]$ & & & \\
\hline Safi 2003 & 18 & 741 & 18 & 263 & $20.4 \%$ & $0.34[0.17,0.66]$ & & & \\
\hline Svensson 1998 & 2 & 17 & 7 & 16 & $6.7 \%$ & $0.17[0.03,1.01]$ & & & \\
\hline Tefera 2000 & 5 & 150 & 12 & 67 & $13.1 \%$ & $0.16[0.05,0.47]$ & & & \\
\hline Total (95\% CI) & & 1319 & & 784 & $100.0 \%$ & $0.42[0.25,0.70]$ & & & \\
\hline \multirow{2}{*}{\multicolumn{7}{|c|}{$\begin{array}{l}\text { Heterogeneity: } \mathrm{Tau}^{2}=0.23 ; \mathrm{Chi}^{2}=14.22, \mathrm{df}=9(\mathrm{P}=0.11) ; \mathrm{I}^{2}=37 \% \\
\text { Test for overall effect: } \mathrm{Z}=3.32(\mathrm{P}=0.0009)\end{array}$}} & & & \\
\hline & & & & & & & $\begin{array}{ll}0.01 & 0.1 \\
\text { Favors CSF Drainage }\end{array}$ & $\begin{array}{c}10 \\
\text { Favors Contro }\end{array}$ & 100 \\
\hline
\end{tabular}

FIG. 2. Forest plot of all studies with their respective RRs and $95 \% \mathrm{Cls}$, events (SCI), and overall RR. M-H = Mantel-Haenszel.

\section{Early SCI Following TAAA Repair}

A total of 6 studies had sufficient information to extract early rates of transient and permanent SCI. One study showed an increase in early SCI when using $\mathrm{CSFD}^{7}$ and the remaining 5 showed a protective benefit. The OR was 0.48 with a $95 \% \mathrm{CI}$ of $0.30-0.76(\mathrm{p}=0.002$; Fig. 4). There was mild heterogeneity as indicated by an $\mathrm{I}^{2}$ statistic of $15 \%$. The absolute risk reduction was $4.3 \%$ with an NNT of 23 .

\section{Late SCI Following TAAA Repair}

A total of 5 studies had sufficient information to extract late rates of transient and permanent SCI. One study showed an increase in late SCI when using $\mathrm{CSFD}^{37}$ and the remaining 4 showed a protective benefit. The OR was 0.73 with a 95\% CI of 0.29-1.81 ( $p=0.49$; Fig. 5). A funnel plot was used to assess publication bias. There was minimal heterogeneity as indicated by an $\mathrm{I}^{2}$ statistic of $0 \%$.

\section{Subgroup Analysis of RCTs}

A total of 3 RCTs were included in the subgroup analysis. Two studies showed a protective benefit when using

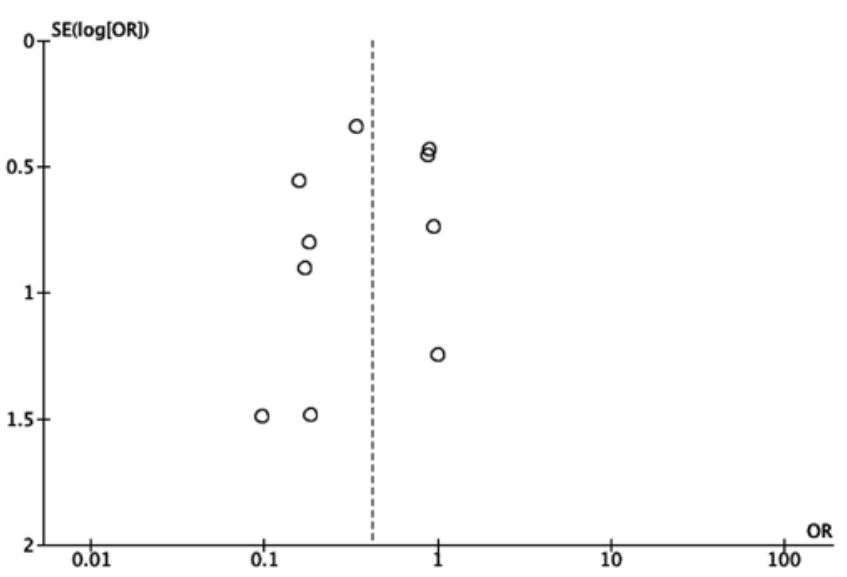

FIG. 3. Funnel plot for evaluating all studies for overall SCI. The absence of studies in the right lower quadrant indicates a lack of small studies that showed increased rates of SCl. SE = standard error.
CSFD in preventing SCI and 1 did not. Using a fixed-effects meta-analysis, the OR was calculated to be 0.48 with a $95 \%$ CI of $0.25-0.92(\mathrm{p}=0.03)$. There was moderate $(\mathrm{p}=0.09)$ heterogeneity as indicated by an $\mathrm{I}^{2}$ statistic of $59 \%$ (Fig. 6).

\section{Complications of CSFD}

Of the 10 studies that met criteria, only 3 reported complications when using lumbar drainage for CSFD. Bisdas et al. reported a requirement of 2 external ventricular drains and 4 episodes of intracranial hypotension. ${ }^{5}$ Coselli et al. reported 2 catheter occlusions/dislodgements. ${ }^{11}$ Svensson et al. reported a persistent CSF leak requiring an epidural blood patch. ${ }^{47}$

\section{Publication Bias and Heterogeneity}

Publication bias was assessed graphically using funnel plots. As shown in Fig. 3 there is a paucity of studies in the right lower quadrant. This quadrant represents small studies that showed an increase in SCI following TAAA repair using CSFD, indicating that publication bias may exist. Minimal heterogeneity was detected as evidenced by the $\mathrm{I}^{2}$ statistics and correlating $\mathrm{p}$ values.

\section{Discussion}

Spinal cord injuries following TAAA repair are significant complications to patients, their families, providers, and the overall health care system. The cardiothoracic literature is mixed when evaluating adjuncts such as CSFD in preventing SCI. Some studies show a benefit, while others do not. This study focuses on nontraumatic SCI in the setting of TAAA repair.

A systematic review performed in 2004 by Cina et al. demonstrated a protective benefit when using CSFD. This study contained 8 included articles and 2 of their studies may have overlapping patient recruitment periods from the same groups of authors. ${ }^{18,39}$ The article by Safi. et al. in 2003 in our study contains the same group of patients as these 2 studies with longer follow-up durations and larger sample sizes. ${ }^{40}$ Thus, our review contains 4 unique articles not presented in their review after more than a decade has elapsed. A Cochrane review in 2012 by Khan et al. looked 


\begin{tabular}{|c|c|c|c|c|c|c|c|c|c|c|}
\hline Study or Subgroup & \multicolumn{2}{|c|}{ Lumbar Drain } & \multicolumn{2}{|c|}{ Control } & Weight & \multirow{2}{*}{$\begin{array}{c}\begin{array}{c}\text { Odds Ratio } \\
\text { M-H, Fixed, 95\% CI }\end{array} \\
0.81[0.22,2.92]\end{array}$} & \multicolumn{4}{|c|}{$\begin{array}{c}\text { Odds Ratio } \\
\text { M-H, Fixed, 95\% Cl }\end{array}$} \\
\hline Bisdas 2015 & 5 & 78 & 5 & 64 & $10.0 \%$ & & & & & \\
\hline Coselli $2002^{11}$ & 1 & 76 & 7 & 69 & $14.1 \%$ & $0.12[0.01,0.99]$ & & & & \\
\hline Crawford 1991 & 10 & 46 & 11 & 52 & $15.8 \%$ & $1.04[0.39,2.72]$ & & & & \\
\hline Hollier 1992 & 0 & 42 & 3 & 108 & $3.8 \%$ & $0.35[0.02,7.01]$ & & & & \\
\hline Murray 1993 & 2 & 47 & 3 & 45 & $5.7 \%$ & $0.62[0.10,3.91]$ & & & & \\
\hline Safi 2003 & 18 & 741 & 18 & 263 & $50.6 \%$ & $0.34[0.17,0.66]$ & & & & \\
\hline Total $(95 \% \mathrm{CI})$ & & 1030 & & 601 & $100.0 \%$ & $0.48[0.30,0.76]$ & & & & \\
\hline Total events & 36 & & 47 & & & & & & & \\
\hline $\begin{array}{l}\text { Heterogeneity: } \mathrm{Chi}^{2}= \\
\text { Test for overall effect }\end{array}$ & $\begin{array}{l}5.89, \mathrm{df}= \\
Z=3.10\end{array}$ & $\begin{array}{l}5(P= \\
=0.0\end{array}$ & $\begin{array}{l}0.32) ; 1^{2} \\
02)\end{array}$ & $=15 \%$ & & & 0.01 & $\begin{array}{l}0.1 \\
\text { Favors CSFD }\end{array}$ & Favors Co & $\begin{array}{l}10 \\
10 \\
\text { ontrol }\end{array}$ \\
\hline
\end{tabular}

FIG. 4. Forest plot of all studies with their respective RRs and $95 \% \mathrm{Cls}$, events (early SCI), and overall RR.

only at RCTs and found 3 included articles ${ }^{11,13,47}$ that are also included in the current study. Khan et al. concluded that there is limited data supporting the role of CSFD in thoracic and TAAA surgery and further studies are needed. ${ }^{31}$ Two of the 3 RCTs of open aortic aneurysm repair included in this study showed benefit when using CSFD. ${ }^{11,47}$ The study by Svensson et al. in 1998 was stopped early by the institutional review board because the interim results show a significant benefit in favor of CSFD and intrathecal papaverine, thus limiting the size of their trial. ${ }^{47}$ In the second trial by Coselli et al. in $2002^{11}$ the rates of SCI significantly decreased from $12.2 \%$ to $2.7 \%(\mathrm{p}=0.03)$, although the observers rating neurological deficit were not blinded. The RCT by Crawford et al. in 1991 did not show a benefit in preventing SCI in those who received CSFD compared with those who did not. ${ }^{13}$ The Crawford study had several important shortcomings. The amount of CSF drained was limited to $50 \mathrm{ml}$ and the CSFD pressure was only reduced to less than $10 \mathrm{~mm} \mathrm{Hg}$ in less than half of the participants. Thus, this trial may not have adequately increased spinal cord perfusion pressure to prevent neurological deficit and answer the hypothesis posed by their study. ${ }^{13}$ Our subgroup fixed-effects meta-analysis shows the same results as described by the Cochrane Review in 2012..$^{31}$

Our study contains 7 articles pertaining to open aortic aneurysmal repair and 3 newer endovascular studies. In the overall analysis we showed a significant protective benefit with moderate but not significant heterogeneity. The overall NNT was 14 with an absolute risk reduction of $7 \%$, which is slightly more modest than the systematic review performed over a decade ago by Cinà et al. that showed an NNT of 11 with an absolute risk reduction of $9 \% .^{8}$ This benefit continued when analyzing early SCI but did not continue when analyzing late SCI. Late neurological deficits may be more a manifestation of a reperfusion type injury and not as directly responsive to increasing spinal cord perfusion pressure by CSFD.

The literature is heterogeneous when evaluating the 3 included endovascular studies. The study by Bisdas et al. showed no improvement in SCI following endovascular repair when prophylactically performing CSFD. However, their protocol for prophylactic versus selective CSFD placement was not uniform and the validity of their results is questionable. ${ }^{5}$ Arnaoutakis et al. did not show a difference when placing a CSF drain compared with the control group, however, both patients who developed SCI responded to CSFD and the authors concluded that the "use of adjunctive procedures for TEVAR [thoracic endovascular aortic repair] demonstrated better SCI results compared with prior reports." Hnath et al. showed a statistically significant benefit when using prophylactic CSFD despite having higher rates of prior TAAA repair, left subclavian artery coverage, increased aortic coverage, and perioperative vasopressors in the CSFD group. ${ }^{27}$ Additional higher quality studies will be needed prior to making any formal recommendations on the use of CSFD in endovascular repair of aortic aneurysms.

The rate of complications related to CSFD was marginal in the included studies. There were reports of nonclinically significant subdural hematoma and external ventricular drain placement. However, there are a multitude of case reports $9,14,24,25,29,33,34$ in the literature citing CSFD

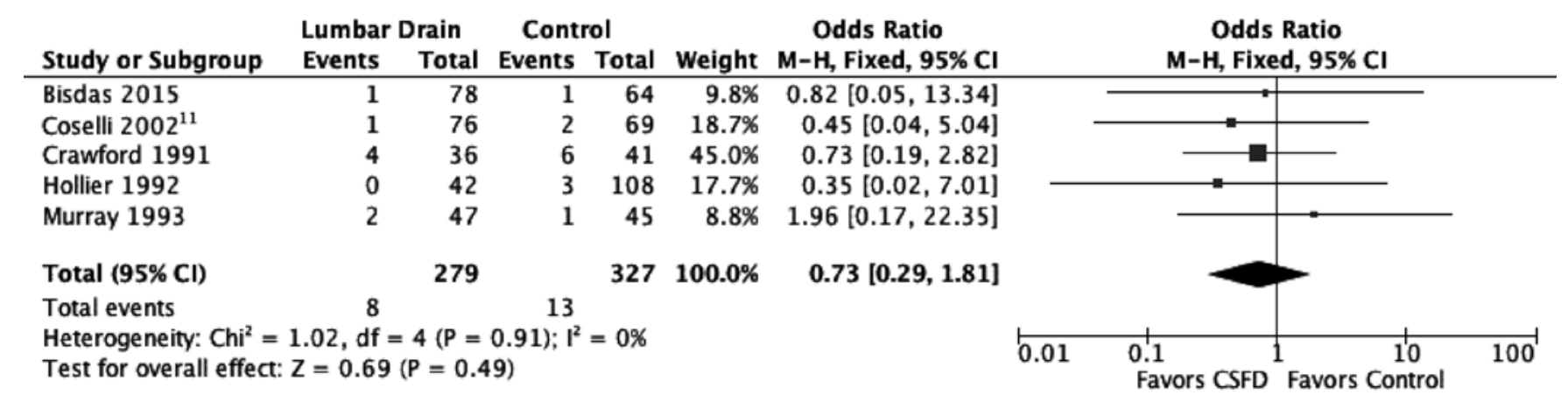

FIG. 5. Forest plot of all studies with their respective RRs and 95\% Cls, events (late SCI), and overall RR. 


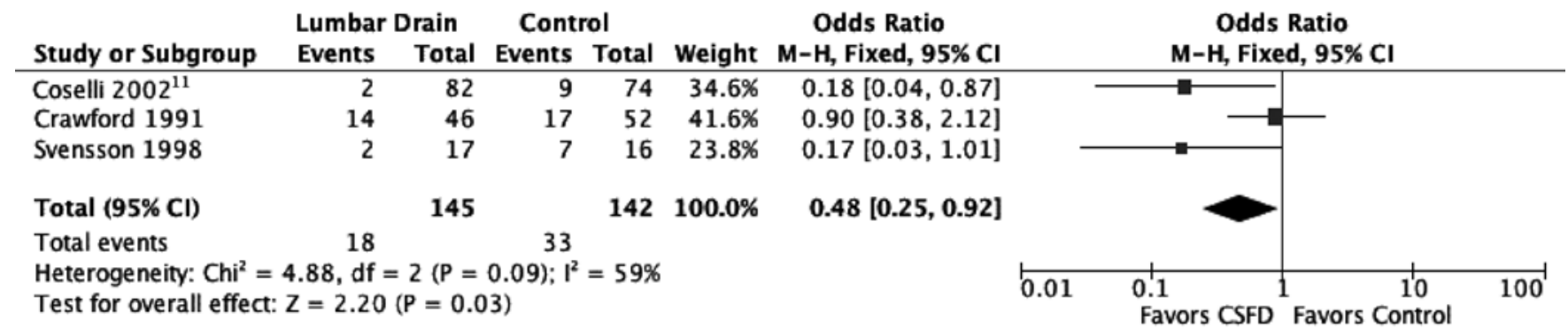

FIG. 6. Forest plot of RCTs with their respective RRs and 95\% Cls, events (SCI), and overall RR.

linked to the development of subdural hematoma following aortic aneurysm repair; 1 report even directly links this complication to the death of the affected patient. ${ }^{33} \mathrm{~A}$ study by Youngblood et al. looking at a series of 504 patients over 5 years receiving CSFD for TAAA repair reported that the rate of intracranial hemorrhage was $2.8 \%$, with the majority being subdural hematomas (72\%), and the postprocedural headache rate was 9.7\%.51 At our own institution we follow a protocol of CSF pressure targeting to $10 \mathrm{~mm} \mathrm{Hg}$ but do not allow greater than $30 \mathrm{ml}$ of CSF to be drained in a single hour to prevent these types of complications.

\section{Limitations and Strengths}

Limitations of our meta-analysis are related to the quality of the included studies. A systematic review and meta-analysis is only as robust as the articles of which it is composed. With only 3 RCTs, the majority of the included data are based on combining prospective and retrospective cohort studies. The quality of the evidence was moderate using objective grading scales. Any selection bias inherent to these nonrandomized studies would be perpetuated in the current analysis. Authors defined neurological deficit heterogeneously. Some authors used sensitive grading scales that likely identified more subtle deficits while others did not. Surgical technique and approach was heterogeneous. To account for heterogeneity in the overall analysis we used a random, instead of a fixed-effects, meta-analysis and formal statistical testing found minimal overall heterogeneity among studies in the outcome of interest. While publication bias may exist, the Cochrane Collaboration recommends against testing for it when a meta-analysis is composed of 10 or fewer studies because when there are fewer studies the power of the tests is too low to distinguish chance from real asymmetry. Until a large, multiinstitutional, prospective RCT is performed, the current meta-analysis represents the highest level of evidence supporting CSFD in TAAA repair.

\section{Conclusions}

Neurosurgeons are often asked to perform CSFD for other consulting services at their discretion. It is prudent for the neurosurgical community to understand the risks, benefits, and indications of this procedure as it relates to the natural history of this disease. Based on moderate quality evidence, the use of CSFD in open TAAA repair may be beneficial with appropriate spinal cord perfusion pressure targeting and appropriate neurological monitoring, but care should be taken to prevent complications related to overdrainage. No firm conclusions can be drawn on the endovascular population at the current time.

\section{Acknowledgments}

We wish to thank Andrew J. Gienapp (Department of Medical Education, Methodist University Hospital, and Department of Neurosurgery, University of Tennessee Health Science Center, Memphis, Tennessee) for technical editing and copyediting, preparation of the manuscript and figures for publishing, and publication assistance with this manuscript.

\section{References}

1. Acher C, Wynn M: Outcomes in open repair of the thoracic and thoracoabdominal aorta. J Vasc Surg 52 (4 Suppl):3S9S, 2010

2. Acher CW, Heisey DM: Regarding "Importance of intercostal artery reattachment during thoracoabdominal aortic aneurysm repair". J Vasc Surg 28:570-571, 1998 (Letter)

3. Acher CW, Wynn MM, Mell MW, Tefera G, Hoch JR: A quantitative assessment of the impact of intercostal artery reimplantation on paralysis risk in thoracoabdominal aortic aneurysm repair. Ann Surg 248:529-540, 2008

4. Arnaoutakis DJ, Arnaoutakis GJ, Beaulieu RJ, Abularrage CJ, Lum YW, Black JH III: Results of adjunctive spinal drainage and/or left subclavian artery bypass in thoracic endovascular aortic repair. Ann Vasc Surg 28:65-73, 2014

5. Bisdas T, Panuccio G, Sugimoto M, Torsello G, Austermann M: Risk factors for spinal cord ischemia after endovascular repair of thoracoabdominal aortic aneurysms. J Vasc Surg 61:1408-1416, 2015

6. Blaisdell FW, Cooley DA: The mechanism of paraplegia after temporary thoracic aortic occlusion and its relationship to spinal fluid pressure. Surgery 51:351-355, 1962

7. Cheung AT, Pochettino A, McGarvey ML, Appoo JJ, Fairman RM, Carpenter JP, et al: Strategies to manage paraplegia risk after endovascular stent repair of descending thoracic aortic aneurysms. Ann Thorac Surg 80:1280-1289, 2005

8. Cinà CS, Abouzahr L, Arena GO, Laganà A, Devereaux PJ, Farrokhyar F: Cerebrospinal fluid drainage to prevent paraplegia during thoracic and thoracoabdominal aortic aneurysm surgery: a systematic review and meta-analysis. J Vasc Surg 40:36-44, 2004

9. Cohen S, Shorshtein A, de La Calzada M, Hunter CW, Solina A: Subarachnoid-cutaneous fistula and subdural hematoma complicating cerebrospinal fluid drainage for thoracoabdominal aorta aneurysm repair. J Clin Anesth 18:475-476, 2006

10. Coselli JS, Conklin LD, LeMaire SA: Thoracoabdominal aortic aneurysm repair: review and update of current strategies. Ann Thorac Surg 74:S1881-S1884, S1892-S1888, 2002 
11. Coselli JS, LeMaire SA, Köksoy C, Schmittling ZC, Curling PE: Cerebrospinal fluid drainage reduces paraplegia after thoracoabdominal aortic aneurysm repair: results of a randomized clinical trial. J Vasc Surg 35:631-639, 2002

12. Coselli JS, LeMaire SA, Schmittling ZC, Köksoy C: Cerebrospinal fluid drainage in thoracoabdominal aortic surgery. Semin Vasc Surg 13:308-314, 2000

13. Crawford ES, Svensson LG, Hess KR, Shenaq SS, Coselli JS, Safi HJ, et al: A prospective randomized study of cerebrospinal fluid drainage to prevent paraplegia after high-risk surgery on the thoracoabdominal aorta. J Vasc Surg 13:36-45, 1991

14. Dardik A, Perler BA, Roseborough GS, Williams GM: Subdural hematoma after thoracoabdominal aortic aneurysm repair: an underreported complication of spinal fluid drainage? J Vasc Surg 36:47-50, 2002

15. DeAnda A, Philpott JM, Kasirajan V: Onlay patch for complete intercostal artery preservation during thoracic and thoracoabdominal aortic aneurysm repair. J Card Surg 20:578-581, 2005

16. DerSimonian R, Laird N: Meta-analysis in clinical trials. Control Clin Trials 7:177-188, 1986

17. Egger M, Davey Smith G, Schneider M, Minder C: Bias in meta-analysis detected by a simple, graphical test. BMJ 315:629-634, 1997

18. Estrera AL, Rubenstein FS, Miller CC III, Huynh TT, Letsou GV, Safi HJ: Descending thoracic aortic aneurysm: surgical approach and treatment using the adjuncts cerebrospinal fluid drainage and distal aortic perfusion. Ann Thorac Surg 72:481-486, 2001

19. Etz CD, Halstead JC, Spielvogel D, Shahani R, Lazala R, Homann TM, et al: Thoracic and thoracoabdominal aneurysm repair: is reimplantation of spinal cord arteries a waste of time? Ann Thorac Surg 82:1670-1677, 2006

20. Etz CD, Kari FA, Mueller CS, Silovitz D, Brenner RM, Lin HM, et al: The collateral network concept: a reassessment of the anatomy of spinal cord perfusion. J Thorac Cardiovasc Surg 141:1020-1028, 2011

21. Etz CD, Luehr M, Kari FA, Bodian CA, Smego D, Plestis KA, et al: Paraplegia after extensive thoracic and thoracoabdominal aortic aneurysm repair: does critical spinal cord ischemia occur postoperatively? J Thorac Cardiovasc Surg 135:324-330, 2008

22. Etz CD, Weigang E, Hartert M, Lonn L, Mestres CA, Di Bartolomeo R, et al: Contemporary spinal cord protection during thoracic and thoracoabdominal aortic surgery and endovascular aortic repair: a position paper of the vascular domain of the European Association for Cardio-Thoracic Surgery. Eur J Cardiothorac Surg 47:943-957, 2015

23. Fehrenbacher JW, Siderys H, Terry C, Kuhn J, Corvera JS: Early and late results of descending thoracic and thoracoabdominal aortic aneurysm open repair with deep hypothermia and circulatory arrest. J Thorac Cardiovasc Surg 140 (6 Suppl):S154-S160, S185-S190, 2010

24. Godet G, Goarin JP, Fléron MH, Bertrand M, Kieffer E, Coriat $\mathrm{P}$ : [Subdural haemorrhage following lumbar spinal drainage during repair of thoraco-abdominal aneurysm.] Ann Fr Anesth Reanim 22:353-358, 2003 (Fr)

25. Hamabe N, Iritakenishi T, Imada T, Mashimo T: [Acute subdural hematoma secondary to cerebrospinal fluid drainage during thoracic endovascular aortic repair (TEVAR): a case report.] Masui 60:1405-1407, 2011 (Jpn)

26. Hanna JM, Andersen ND, Aziz H, Shah AA, McCann RL, Hughes GC: Results with selective preoperative lumbar drain placement for thoracic endovascular aortic repair. Ann Thorac Surg 95:1968-1975, 2013

27. Hnath JC, Mehta M, Taggert JB, Sternbach Y, Roddy SP, Kreienberg PB, et al: Strategies to improve spinal cord ischemia in endovascular thoracic aortic repair: Outcomes of a prospective cerebrospinal fluid drainage protocol. J Vasc Surg 48:836-840, 2008

28. Hollier LH, Money SR, Naslund TC, Proctor CD Sr, Buhrman WC, Marino RJ, et al: Risk of spinal cord dysfunction in patients undergoing thoracoabdominal aortic replacement. Am J Surg 164:210-214, 1992

29. Ishikawa N, Omoto T, Oi M, Fukuzumi M, Iizuka H, Kawaura $\mathrm{H}$, et al: Acute subdural hematoma following thoracoabdominal aortic repair in a patient with Marfan syndrome: a rare complication of cerebrospinal fluid drainage. Ann Thorac Cardiovasc Surg 18:488-490, 2012

30. Jadad AR, Moore RA, Carroll D, Jenkinson C, Reynolds DJ, Gavaghan DJ, et al: Assessing the quality of reports of randomized clinical trials: is blinding necessary? Control Clin Trials 17:1-12, 1996

31. Khan SNSG, Stansby G: Cerebrospinal fluid drainage for thoracic and thoracoabdominal aortic aneurysm surgery. Cochrane Database Syst Rev 10:CD003635, 2012

32. Kouchoukos NT, Kulik A, Castner CF: Outcomes after thoracoabdominal aortic aneurysm repair using hypothermic circulatory arrest. J Thorac Cardiovasc Surg 145 (3 Suppl):S139-S141, 2013

33. McHardy FE, Bayly PJ, Wyatt MG: Fatal subdural haemorrhage following lumbar spinal drainage during repair of thoraco-abdominal aneurysm. Anaesthesia 56:168-170, 2001

34. Mehmedagic I, Resch T, Acosta S: Complications to cerebrospinal fluid drainage and predictors of spinal cord ischemia in patients with aortic disease undergoing advanced endovascular therapy. Vasc Endovascular Surg 47:415-422, 2013

35. Miyamoto K, Ueno A, Wada T, Kimoto S: A new and simple method of preventing spinal cord damage following temporary occlusion of the thoracic aorta by draining the cerebrospinal fluid. J Cardiovasc Surg (Torino) 1:188-197, 1960

36. Moher D, Liberati A, Tetzlaff J, Altman DG: Preferred reporting items for systematic reviews and meta-analyses: the PRISMA statement. PLoS Med 6:e1000097, 2009

37. Murray MJ, Bower TC, Oliver WC Jr, Werner E, Gloviczki P: Effects of cerebrospinal fluid drainage in patients undergoing thoracic and thoracoabdominal aortic surgery. J Cardiothorac Vasc Anesth 7:266-272, 1993

38. Safi HJ, Estrera AL, Miller CC, Huynh TT, Porat EE, Azizzadeh A, et al: Evolution of risk for neurologic deficit after descending and thoracoabdominal aortic repair. Ann Thorac Surg 80:2173-2179, 2005

39. Safi HJ, Miller CC III: Spinal cord protection in descending thoracic and thoracoabdominal aortic repair. Ann Thorac Surg 67:1937-1939, 1953-1958, 1999

40. Safi HJ, Miller CC III, Huynh TT, Estrera AL, Porat EE, Winnerkvist AN, et al: Distal aortic perfusion and cerebrospinal fluid drainage for thoracoabdominal and descending thoracic aortic repair: ten years of organ protection. Ann Surg 238:372-381, 2003

41. Schepens M, Dossche K, Morshuis W, Heijmen R, van Dongen $\mathrm{E}$, Ter Beek H, et al: Introduction of adjuncts and their influence on changing results in 402 consecutive thoracoabdominal aortic aneurysm repairs. Eur J Cardiothorac Surg 25:701-707, 2004

42. Shea BJ, Grimshaw JM, Wells GA, Boers M, Andersson N, Hamel C, et al: Development of AMSTAR: a measurement tool to assess the methodological quality of systematic reviews. BMC Med Res Methodol 7:10, 2007

43. Sterne JA, Egger M: Funnel plots for detecting bias in metaanalysis: guidelines on choice of axis. J Clin Epidemiol 54:1046-1055, 2001

44. Sterne JA, Egger M, Smith GD: Systematic reviews in health care: Investigating and dealing with publication and other biases in meta-analysis. BMJ 323:101-105, 2001

45. Stroup DF, Berlin JA, Morton SC, Olkin I, Williamson GD, Rennie D, et al: Meta-analysis of observational studies in epidemiology: a proposal for reporting. Meta-analysis Of 
Observational Studies in Epidemiology (MOOSE) group. JAMA 283:2008-2012, 2000

46. Svensson LG, Crawford ES, Hess KR, Coselli JS, Safi HJ: Experience with 1509 patients undergoing thoracoabdominal aortic operations. J Vasc Surg 17:357-370, 1993

47. Svensson LG, Hess KR, D’Agostino RS, Entrup MH, Hreib $\mathrm{K}$, Kimmel WA, et al: Reduction of neurologic injury after high-risk thoracoabdominal aortic operation. Ann Thorac Surg 66:132-138, 1998

48. Tefera G, Acher CW, Wynn MM: Clamp and sew techniques in thoracoabdominal aortic surgery using naloxone and CSF drainage. Semin Vasc Surg 13:325-330, 2000

49. Wells GA, Shea B, O'Connell D, Peterson J, Welch V, Losos M, et al: The Newcastle-Ottawa Scale (NOS) for assessing the quality of nonrandomised studies in meta-analyses. The Ottawa Hospital Research Institute. (http://www.ohri.ca/ programs/clinical_epidemiology/oxford.asp) [Accessed January 28, 2016]

50. Wong DR, Parenti JL, Green SY, Chowdhary V, Liao JM, Zarda S, et al: Open repair of thoracoabdominal aortic aneurysm in the modern surgical era: contemporary outcomes in 509 patients. J Am Coll Surg 212:569-581, 2011

51. Youngblood SC, Tolpin DA, LeMaire SA, Coselli JS, Lee VV, Cooper JR Jr: Complications of cerebrospinal fluid drainage after thoracic aortic surgery: a review of 504 patients over 5 years. J Thorac Cardiovasc Surg 146:166-171, 2013

\section{Disclosures}

The authors report no conflict of interest concerning the materials or methods used in this study or the findings specified in this paper.

\section{Author Contributions}

Conception and design: Khan. Acquisition of data: Michael, Khan, Smalley, Nesvick. Analysis and interpretation of data: all authors. Drafting the article: all authors. Critically revising the article: all authors. Reviewed submitted version of manuscript: Michael, Khan, Lee. Approved the final version of the manuscript on behalf of all authors: Michael. Statistical analysis: Khan. Study supervision: Michael.

\section{Correspondence}

L. Madison Michael II, Semmes-Murphey Neurologic \& Spine Clinic, 847 Monroe Ave., Ste. 427, Memphis, TN 38120. email: mmichael@semmes-murphey.com. 